\section{Commentary: Perhaps less is more: Definitive surgical management of aortoesophageal fistulas}

\author{
Lisa M. Brown, MD, MAS, FACS
}

One of the most complex cardiothoracic surgical scenarios is the aortoesophageal fistula (AEF). AEFs are classified as either primary or secondary, with primary AEF caused by aortic aneurysm or aortic rupture or esophageal cancer, perforation, or foreign body and secondary AEF occurring as a complication of either thoracic aortic or esophageal surgery. ${ }^{1}$ The most conservative approach to management is immediate endovascular repair and broad-spectrum antibiotics followed by esophagectomy, aortic replacement, and later restoration of upper gastrointestinal continuity. Many reports on AEF are literature reviews, including a number of case series, owing to the rarity of this problem. ${ }^{2-5}$ An advantage of these reviews is that the smaller case series pooled together add up to a relatively large cohort, allowing for statistical analyses and corresponding conclusions. For example, all 47 patients presented during an AEF symposium at the 65th Annual Scientific Meeting of the Japanese Association for Thoracic Surgery were included in a retrospective cohort study aimed at identifying the optimal treatment strategy for AEF; the clinical end points were 6- and 18-month mortality. ${ }^{2}$ Esophagectomy, open aortic replacement with either prosthetic or homograft, and use of an omental flap were associated with improved survival. $^{2}$

Given the broad range of etiologies for AEF, patient-level factors predictive of survival, and the need to address both

\footnotetext{
From the Section of General Thoracic Surgery, University of California, Davis Health, Sacramento, Calif.

Disclosures: The author reported no conflicts of interest.

The Journal policy requires editors and reviewers to disclose conflicts of interest and to decline handling or reviewing manuscripts for which they may have a conflict of interest. The editors and reviewers of this article have no conflicts of interest.

Received for publication July 4, 2020; revisions received July 4, 2020; accepted for publication July 6, 2020; available ahead of print July 11, 2020.

Address for reprints: Lisa M. Brown, MD, MAS, FACS, University of California, Davis Health, North Addition Office Building, 2335 Stockton Blvd, Room 6122, Sacramento, CA 95814 (E-mail: lmbrown@ucdavis.edu).

J Thorac Cardiovasc Surg 2022;163:2009

$0022-5223 / \$ 36.00$

Copyright (c) 2020 by The American Association for Thoracic Surgery

https://doi.org/10.1016/j.jtcvs.2020.07.004
}

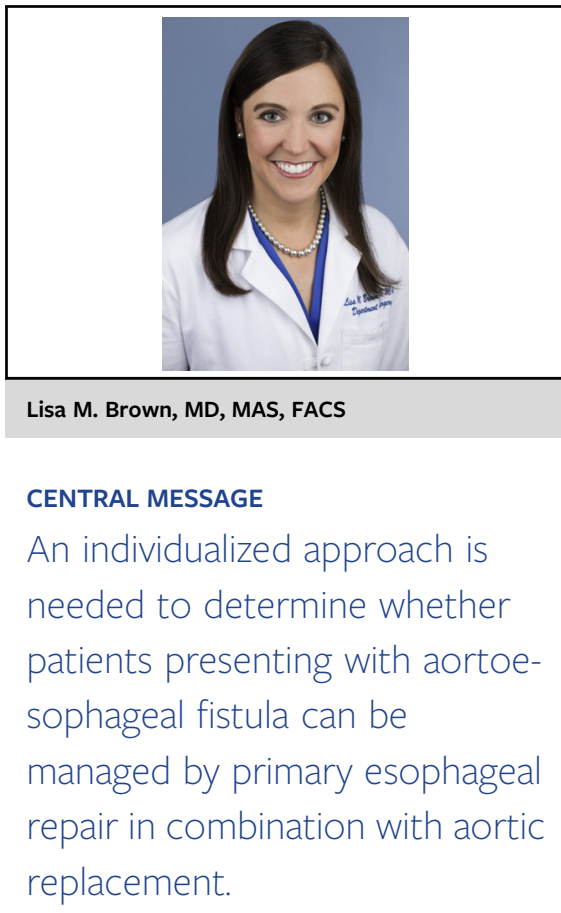

the aorta and esophagus, there is certainly a role for publication of small, detailed case series as important clinical nuances are lost in pooled analyses. In this issue of the Journal, Jeon and colleagues ${ }^{1}$ present details on the surgical management of 10 patients presenting with AEF. Their preference was for in situ replacement of the aortic segment with a cryopreserved homograft and, if this was not available, they used a prosthetic graft. Interestingly, they attempted primary repair of the esophagus at the same time as aortic replacement. ${ }^{1}$ If the esophageal primary repair failed, they used endoluminal vacuum-assisted therapy and, if this failed, they did an esophagectomy followed by reconstruction later. ${ }^{1}$ Given the need to evaluate both the success of the aortic replacement and esophageal repair in these cases, it is important to analyze the outcomes of patients according to the combination of operations that was done. All 3 of the patients who underwent aortic replacement with homograft and primary repair of the esophagus survived and resumed oral intake, whereas only 1 of the 3 patients undergoing aortic replacement with a prosthetic graft and primary repair of the esophagus survived and resumed oral intake; the other 2 died. ${ }^{1}$ Endoscopic evaluation of 1 of these 2 patients who died revealed a nearly healed esophageal repair and the cause of death was sepsis from another source. ${ }^{1}$ The authors report a relatively high success rate with the combination of aortic replacement with either 
prosthetic or homograft and primary repair of the esophagus and conclude that this approach is both feasible and promising. ${ }^{1}$ Clearly, as the authors point out, the decision to primarily repair the esophagus must be made on an individualized basis, given the clinical circumstances.

\section{References}

1. Jeon YJ, Kim HK, Kim WS, Cho JH, Sung K. Repair of aortoesophageal fistula with homograft aortic replacement and primary esophageal closure. J Thorac Cardiovasc Surg. 2022;163:2002-8.
2. Akashi H, Kawamoto S, Saiki Y, Sakamoto T, Sawa Y, Tsukube T, et al. Therapeutic strategy for treating aortoesophageal fistulas. Thorac Cardiovasc Surg. 2014; 62:573-80.

3. Canaud L, Ozdemir BA, Bee WW, Bahia S, Holt P, Thompson M. Thoracic endovascular aortic repair in management of aortoesophageal fistulas. J Vasc Surg. 2014;59:248-54.

4. Kotelis D, Gombert A, Jacobs MJ. Treatment of post-thoracic endovascular aortic repair aorto-esophageal fistula — only radical surgery can be effective: techniques and sequence of treatment. J Thorac Dis. 2018;10:3869-73.

5. Takeno S, Ishii H, Nanashima A, Nakamura K. Aortoesophageal fistula: review of trends in the last decade. Surg Today. December 16, 2019 [Epub ahead of print].
See Article page 2002.

\section{Commentary: Aortoesophageal fistulas for 500: What is Monday morning quarterbacking?}

\author{
Carlos J. Anciano, MD, and \\ Mark D. Iannettoni, MD, MBA
}

Aortoesophageal fistula is an infrequent medical conundrum and surgical catastrophe. Despite advances in care and technologies, they remain an efficient assassin. Nonsurgical intervention or sole medical therapy are uniformly fatal. ${ }^{1,2}$ Surgical therapies retain a high morbidity as well as considerable early and delayed mortality. These patients often present with severe comorbidities, sepsis, and hemodynamic compromise. Jeon and colleagues ${ }^{3}$ present their institution's retrospective review of 10 cases of aortoesophageal fistula of various etiologies spanning a little over a decade managed with their favored approach of interposition aortic homograft replacement and primary esophageal repair. Etiologies, as usual, vary between primary aortic ruptures and aneurysms, esophageal rupture, and

From the Division of Thoracic and Foregut Surgery, East Carolina University, Greenville, NC.

Disclosures: The authors reported no conflicts of interest.

The Journal policy requires editors and reviewers to disclose conflicts of interest and to decline handling or reviewing manuscripts for which they may have a conflict of interest. The editors and reviewers of this article have no conflicts of interest.

Received for publication July 9, 2020; revisions received July 9, 2020; accepted for publication July 10, 2020; available ahead of print July 15, 2020.

Address for reprints: Carlos J. Anciano, MD, Division of Thoracic and Foregut Surgery, East Carolina University, 115 Heart Dr, Greenville, NC 27834 (E-mail: ancianoc14@ecu.edu).

J Thorac Cardiovasc Surg 2022;163:2010-1

$0022-5223 / \$ 36.00$

Copyright (c) 2020 by The American Association for Thoracic Surgery

https://doi.org/10.1016/j.jtcvs.2020.07.031

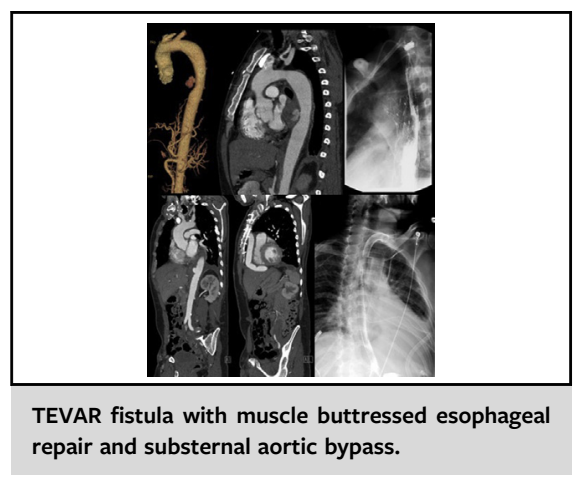

CENTRAL MESSAGE

Aortoesophageal fistula is lethal despite advancements. Medical

optimization, radical versus

staged repairs, in situ versus

extra-anatomic vasculoenteric

repair, and conduit choice influ-

ence outcomes.

secondary to open aortic graft replacements or endovascular thoracic aortic stenting. Interposition graft replacement was completed in 9 instances, but the preferred homograft used only in 5, albeit without mortality in the reported timeframes. Primary esophageal repair by layers, irrigation, and wide mediastinal drainage was the treatment of choice for the foregut injury with follow-up endoluminal vacuum assistance when required. Three patients underwent forms of esophagectomy. There were 2 deaths in the series corresponding to prosthetic graft replacement instances in settings of sepsis.

Frequently with uncommon disorders, case groupings to evaluate common factors positively influencing outcomes is 